\title{
Indirect Tensile Characterization of Graphite Platelet Reinforced Vinyl Ester Nanocomposites at High-Strain Rate
}

\author{
Brahmananda Pramanik', P. Raju Mantena², Tezeswi Tadepalli3 ${ }^{3}$, \\ Arunachalam M. Rajendran ${ }^{2}$ \\ ${ }^{1}$ Department of General Engineering, Montana Tech of the University of Montana, Butte, MT, USA \\ ${ }^{2}$ Department of Mechanical Engineering, University of Mississippi, University, MS, USA \\ ${ }^{3}$ Department of Civil Engineering, National Institute of Technology, (NIT), Warangal, India \\ Email: bpramanik@mtech.edu, meprm@olemiss.edu, tezeswi@nitw.ac.in, raj@olemiss.edu
}

Received 2 July 2014; revised 2 August 2014; accepted 30 August 2014

Copyright (C) 2014 by authors and Scientific Research Publishing Inc.

This work is licensed under the Creative Commons Attribution International License (CC BY).

http://creativecommons.org/licenses/by/4.0/

(c) (i) Open Access

\section{Abstract}

An indirect tensile testing method is proposed for characterizing low strength graphite platelet reinforced vinyl ester nanocomposites at high-strain rate. In this technique, the traditional Brazilian disk (diametrical compression) test method for brittle materials is utilized along with conventional split-Hopkinson pressure bars (SHPB) for evaluating cylindrical disk specimens. The cylindrical disk specimen is held snugly in between two concave end fixtures attached to the incident and transmission bars. To eliminate the complexities of conventional strain gage application, a non-contact Laser Occluding Expansion Gage (LOEG) has been adapted for measuring the diametrical transverse expansion of the specimen under high-strain rate diametrical compressive loading. Failure diagnosis using high-speed digital photography validates the viability of utilizing this indirect test method for characterizing the tensile properties of XGnP (exfoliated graphite nanoplatelets) reinforced and additional CTBN (Carboxyl Terminated Butadiene Nitrile) toughened vinyl ester based nanocomposites. Also, quasi-static indirect tensile response agrees with previous investigations conducted using the traditional dog-bone specimen in direct tensile tests. Investigation of both quasi-static and dynamic indirect tensile test responses shows the strain rate effect on the tensile strength and energy absorbing capacity of the candidate materials. The contribution of reinforcement to the tensile properties of the candidate materials is presented.

\section{Keywords}

Split Hopkinson Pressure Bars, High-Strain Rate Tensile Test, Brazilian Disk Test Method, Laser Occluding Expansion Gage, Nanocomposites 


\section{Introduction}

Robust material models obtained from the physics of high-stain rate material response are essential for the large scale finite element simulations of automotive crashworthiness; aerospace impact including foreign-object damage, such as, bird ingestion in jet engines and meteorite impact on satellites; dynamic structural loading, such as, the events occur during earthquakes; high-rate manufacturing processes, including high-rate forging, machining, wire drawing and cold rolling; and research for military technologies focusing on ballistics, detonation physics, projectile and armor interactions [1]. One of the most widely used experimental configurations for high-strain rate material response measurements is the split-Hopkinson pressure bar (SHPB) conceived by Hopkinson [2] and Davies [3], with Kolskey [4] proposing the first acceptable form of SHPB in a laboratory.

While the original SHPB was developed to measure the compressive response of materials, measurement of the tensile response under dynamic loading becomes important due to the uniqueness of corresponding material properties. Harding et al. [5] first attempted to adapt the Hopkinson-Kolskey bar for measuring high-strain rate tensile response of the test specimen. Not only the complexity of generating a tensile-loading pulse, but also designing the tensile test specimen geometry and specimen-holding fixtures were addressed by multiple researchers [6]-[18]. The pressure bar-ends need major modification to accommodate tensile specimens of complex geometries. The variations of the cross-sections at pressure bar ends develop complex stress pulse. All these issues require special attention in experimental data reduction process.

Vinyl ester based composites are being considered in applications such as pipelines and chemical storage tanks and ship hulls. Figure 1 shows the idealized chemical structure of a typical vinyl ester. As the reactive sites are positioned only at the ends of the molecular chains, the long molecular chain makes vinyl ester resin tough and resilient to shock loadings (to some extent). The ester groups in the molecular structure are susceptible to water degradation by hydrolysis. The vinyl ester molecule features fewer ester groups; hence, exhibits better resistance to water and to some chemicals [20] [21]. Several attempts [21]-[33] have focused on improving the mechanical properties of vinyl ester composites by providing reinforcement. Graphite nanoplatelet reinforcement and toughening with CTBN liquid-rubber agent have been recently considered for this composite system. In previous research conducted by the authors [34]-[38], it has been observed that the candidate composite systems are high in stiffness, but low in strength, and fail in a brittle fashion. It is observed that the failure of high stiffness and low strength materials is initiated by tensile stress concentrations. Hence the investigation of the dynamic response of such materials under high strain-rate tensile loading requires serious consideration.

Tensile tests on high-stiffness low-strength materials usually resort to compression-induced tension in order to avoid pre-mature failure caused from gripping under direct tensile loading. Almost at the same time from opposite sides of the world, Carneiro [39] from Brazil and Akazawa [40] from Japan independently proposed that the circular disk theory (analytically explained by Timoshenko and Goodier [41]) could be applicable in investigating the bearing capacity of a concrete roller. They explained that the specimen ruptures along the diametrical plane and the tensile stress at the center of the disk could be estimated as a function of the applied bearing load, the diameter of the specimen and the specimen thickness.

The specimen strain measurement at high rates is traditionally based on the response from strain gages mounted on the bars of a SHPB system. This technique only works for obtaining the longitudinal strain measurements. In case of Brazilian test method, transverse strain measurement is the primary requirement. Hence, strain gages need to be mounted on the specimen surface along the transverse axis, or, alternatively, a high-

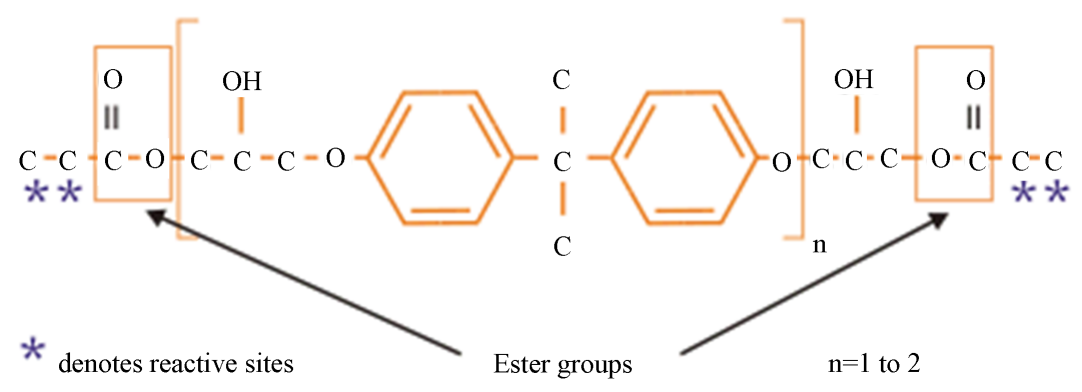

Figure 1. Chemical structure of a typical epoxy based vinyl ester [19]. 
speed camera combined with Digital Image Correlation (DIC) techniques can be utilized. Both of these methods are complex in installation, expensive and the data reduction processes are also cumbersome.

In this article, an indirect tensile testing method is proposed for characterizing low strength graphite platelet reinforced vinyl ester nanocomposites at high-strain rate. The cylindrical disk specimen is evaluated by traditional Brazilian disk test method combined with conventional SHPB technique. The disk specimen is securely held and self-aligned in two concave-end loading fixtures assembled in between the incident and transmission bars of SHPB system. The complexities of conventional strain gage application on the specimen for measuring the diametrical transverse expansion of the specimen under high-strain rate diametrical compressive loading are eliminated by adapting a non-contact LOEG technique [42] [43]. High-speed digital photography is performed for diagnosing the specimen failure mechanism and validating the indirect test method for characterizing the tensile properties of graphite platelet reinforced and additionally CTBN toughened vinyl ester nanocomposites. Finally, the effect of strain rate and the contribution of $\mathrm{xGnP}$ reinforcement and CTBN toughening on the tensile properties of vinyl ester based nanocomposites are presented.

\section{Experimental Set-Up}

Experimental facilities used in this study consist of a traditional compression split-Hopkinson pressure bar system that has been modified to conduct indirect dynamic tensile tests on nanocomposite specimens based on conventional Brazilian disk test method. A conventional pneumatically driven materials test system (EnduraTec) was used for the quasi-static indirect tensile experiments.

\subsection{SHPB Apparatus}

The SHPB system (Figure 2) was driven by a compressed air vessel connected with a solenoid switch valve to one end of the steel barrel having convex-end solid cylindrical striker. The overall system consists of an incident bar, a transmission bar, momentum bar and a momentum-trap made of white putty clay packed in a robust steel frame. The bars and the striker are made from $19 \mathrm{~mm}$ diameter (0.75 inch) Aluminum bars [43].

Two sets of $350 \Omega$ strain gages were attached at a distance away from the specimen on the incident and transmitted bars allowing the strain gages to capture the initiation of the incident, reflected and transmitted pulses distinctly (Figure 2). Each set consists of two gages located diametrically opposite side of the bar and connected in series to compensate the bending effect of the bars and measure only axial strain of the bars. A digital oscilloscope of 1.25 GS sampling rate, connected to strain gages through a Wheatstone bridge and a signal conditioner, records the corresponding voltage-time history during the test event.

\subsection{Adaptation of Brazilian Disk Test System}

The Brazilian disk test method [39] is an efficient indirect approach for obtaining the tensile strength of highstiffness low-strength brittle materials. It assumes a state of plane stress in the disk due to the application of diametrically opposite loading on the disk specimen [39] [40]. The tensile stress [39]-[41] induced at the center of the specimen along the transverse diameter of the disk specimen has been analytically and experimentally determined as $2 P /(\pi D L)$, where, $P$ is the applied compressive load, $D$ is the diameter of the specimen, $L$

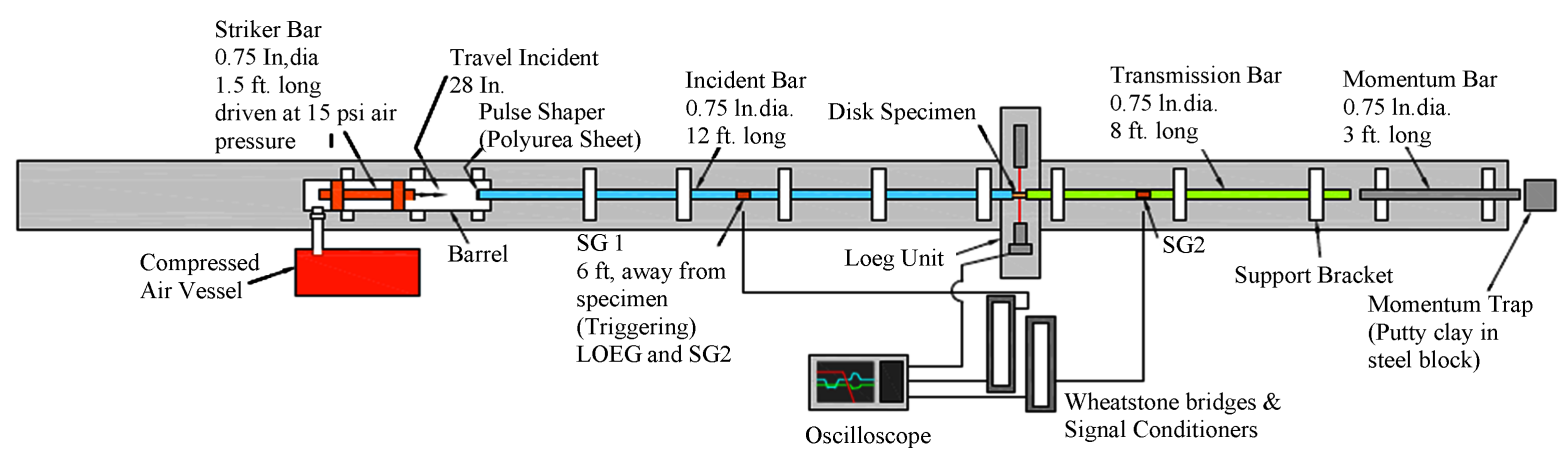

Figure 2. SHPB setup for indirect tensile tests including Laser Occluding Expansion Gage (LOEG) system. 
is the specimen thickness.

Conventional Brazilian disk method proposes flat-end anvils for loading the circular disk specimen. The disadvantage of this approach is a large stress concentration at the loading lines along the thickness of the specimen. Hence, in most of the cases premature failure occurs close to the loading lines [45]. Two controlled loading approaches have been tried in this investigation. The geometry of the disk specimen was modified in the first attempt. The diametrically opposite loading lines along the thickness of the specimen were made flat [46] for about $20^{\circ}$ angle subtended at the center of the specimen to decentralize the stress concentration at the loading point and hence the relation of induced tensile stress with applied compressive load was modified based on the subtended angle by the flat-ends. The disadvantage of this approach is that the specimens rupture at the edges of the flat-ends, instead of at the center of the specimen. It was observed that the flatness and parallelism of the flat ends are crucial for the success. High precision in specimen preparation is required for this approach and achieving that level of geometric accuracy is practically difficult in case of quasi-brittle materials.

The second approach eliminates all these complexities by modifying the flat-end of anvil to circular concave ends [45]. Also the concave ends hold the disk specimen more securely than flat-ends in horizontal SHPB testing. The stress concentration is optimally reduced with failure of the disk specimen initiating at the disk-center and propagating along the compressive loading axis, thus ensuring a valid indirect tensile test (Figure 3).

The incident and transmission bars were threaded in and coupled with respective concave-end fixtures. The disk specimen was diametrically held in between the larger diameter concaved surfaces of the loading fixtures.

\subsection{Validation of Test Set-Up}

A fundamental requirement for the validation of the Brazilian disk test method is that the initiation of specimen failure should occur at the center of the specimen and propagates through the diameter along the compressive loading axis [39]. At high strain rate loading, the failure occurs within micro- to milli-second depending on the brittleness of the material. Human eye is able to persistently and distinguishably observe only such dynamic events that takes more than 40 milli-seconds [47] and even cannot record this event; hence a high-speed camera is essential in this validation process. A sample specimen of $19 \mathrm{~mm}(0.75 \mathrm{inch})$ diameter was tested at $10 \mathrm{psi}$ reservoir pressure to ensure the recording of the diametrical fracture phenomena according to the scope of the high-speed camera (Hadland HPV-2 Shimadzu). The camera was operated at 250,000 fps. The dynamic event was captured in 102 image-frames with $1 \mu$ s exposure. The specimen expanded along the transverse diameter and the failure occurred through the diameter along the compressive loading axis (Figure 4) within 48 to $52 \mu$ s. The fracture initiated at the center of the specimen and propagated through the diameter along the loading axis towards the points of loading. The maximum expansion occurred along transverse diameter of the specimen, which validated the experimental setup for characterizing the tensile properties of the materials under compressive diametrical loading.

\subsection{Stress Measurement Technique}

The striker bar was launched by elevated air pressure, resulting in a one-dimensional incident stress wave in incident bar. The strains ( $\varepsilon_{i}$ and $\varepsilon_{r}$ ) developed in the incident bar due to the consequent incident and reflected

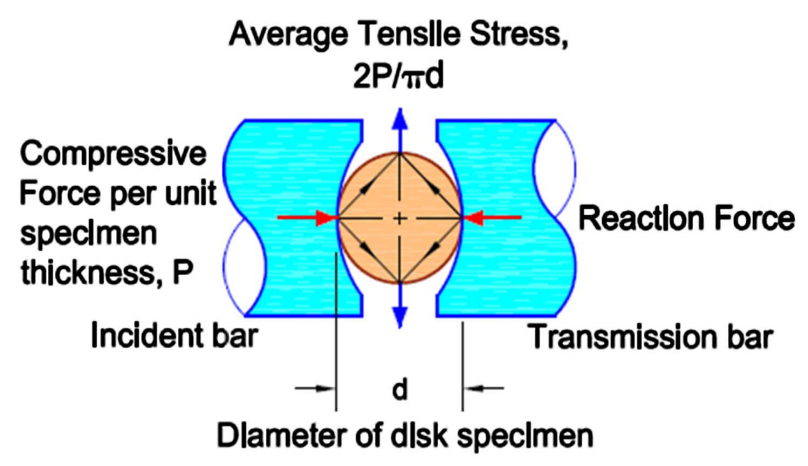

Figure 3. Induced tensile stress in circular disk specimen along transverse direction due to applied compressive loading. 


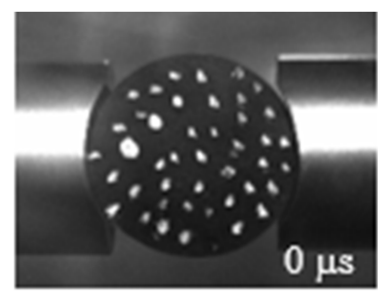

Horizontal loading

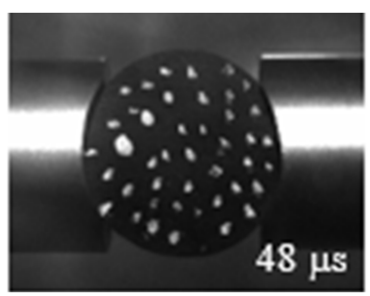

Transverse deformation

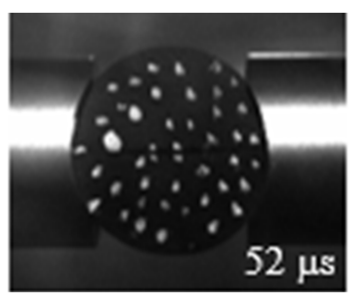

Fracture initiation

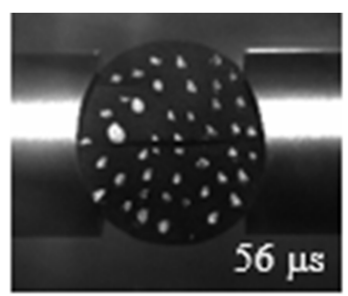

Multiple Fractures

Figure 4. High-speed digital images of the specimen failure due to transverse tensile stress induced by high-strain rate diametric compressive loading (white spots on specimens are for performing 2D-DIC in image processing software for further analysis).

stress waves were measured by the strain gages mounted on the incident bar and similarly the strain $\left(\varepsilon_{t}\right)$ developed on the transmission bar due to the transmitted stress wave (subscript $t$ ) measured by the strain gages mounted on the transmission bar. The forces on the two ends of the specimen along the SHPB loading axis [48] were estimated by the following equation:

$$
F_{1}=A E\left(\varepsilon_{i}+\varepsilon_{r}\right) \text { and } F_{2}=A E \varepsilon_{t}
$$

where $E$ is elastic modulus of the bar material, $A$ is the cross-sectional area of the bar and $\varepsilon$ denotes strain. The average of the end forces were considered for estimating the average dynamic tensile stress induced at the center of the Brazilian disk specimen along the orthogonal diameter of the loading axis using Equation (2) according to the circular disk theory [39]-[41].

$$
\sigma_{d t}=\frac{F_{1}+F_{2}}{\pi D b}
$$

where, $D$, and $b$, are the diameter and the thickness of the disk specimen.

A pulse shaper was employed to achieve dynamic force balance in the specimen during the experiment. In a traditional SHPB test, the incident wave with rectangular stress-pulse may initiate undesired damage to the specimen upon impact before achieving stress equilibrium. If forces on both sides of the specimen are not the same during test event, the test cannot be considered as valid [49]. A polyurea disk, 0.313 inch in diameter and 0.003 inch in thickness, was used for shaping the incident wave from a rectangular to a trapezoidal wave (Figure 5(a)). This rubbery pulse shaper ramped the incident pulse such that the tensile stresses induced in the disk specimen achieved an equilibrium state before diametrical splitting of the specimen occurred. Figure 5(b) shows the pulses on both ends of the specimen obtained in a typical test. The dynamic force $\left(F_{1}\right)$ on the end of the specimen towards incident bar is proportional to the sum of the incident and reflected stress waves, and the dynamic force $\left(F_{2}\right)$ on the other end of the specimen towards transmission bar is proportional to the transmitted stress wave. It can be seen from Figure 5(b) that the dynamic pulses responsible for these two forces on both sides of the specimen remained almost identical during the whole dynamic loading period. The inertial effects were thus eliminated due to the absence of global force difference in the specimen. Hence, the static equilibrium analysis is valid [41] for this test method.

\subsection{Strain Measurement Technique}

The diametrical transverse strain of the disk specimen was measured using a Laser Occluding Expansion Gage. LOEG works on the principle of occluding a thin parallel sheet of laser passing over the deforming specimen under dynamic loading [42] [50]. The full-field potential output due to the non-occluded laser was recorded as the base-line potential for a measurement. Any occlusion of laser due to the presence and subsequent deformation of the specimen across the path of laser sheet was depicted as the drop of potential. The specimen-strain was directly predicted from the ratio of the increment of drop of potential $(\delta \mathrm{V})$ during specimen deformation to the initial drop of potential $(V)$ due to the placement of the specimen across the path of laser sheet.

A comparative study was performed through installing a strain gage (EA-06-062DN-350) on the disk specimen and obtaining indirect tensile strain simultaneously using LOEG setup and on-specimen strain gage (Figures 6(a)-(c)). The single strain gage was mounted on one side of the disk specimen and connected in quarter bridge 


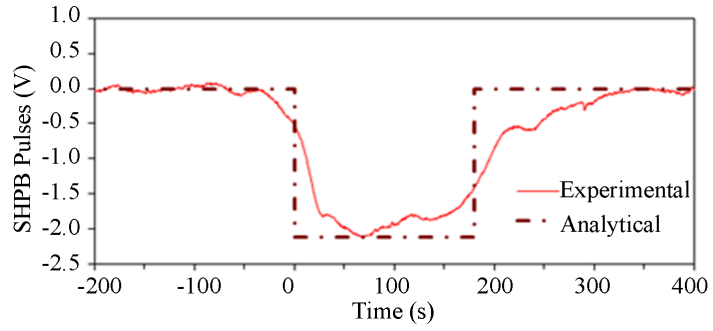

(a)

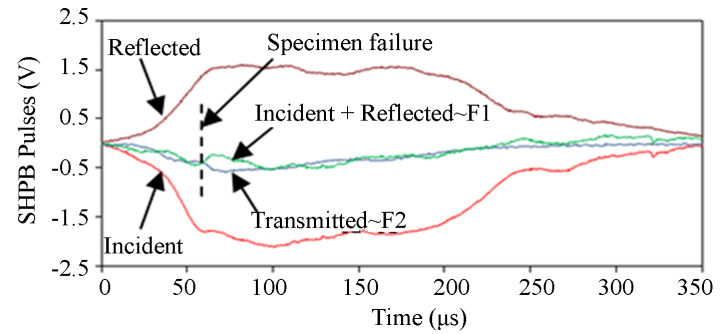

(b)

Figure 5. (a) Typical incident pulse applied in high strain rate indirect tensile test; (b) Dynamic force balance during a typical high-strain rate indirect tensile test.

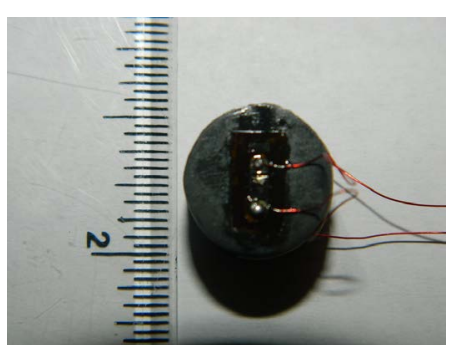

(a)

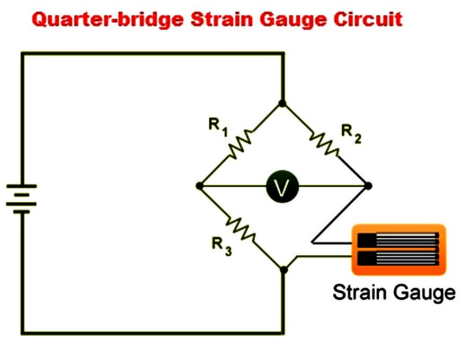

(b)

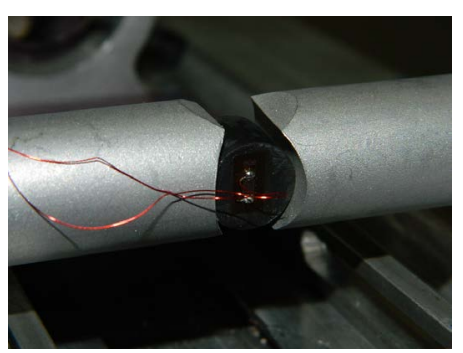

(c)

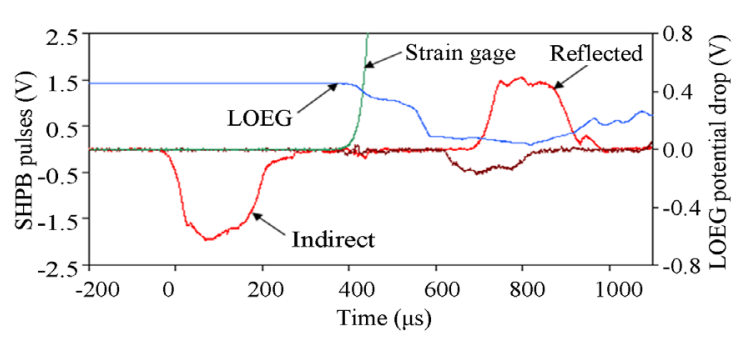

(d)

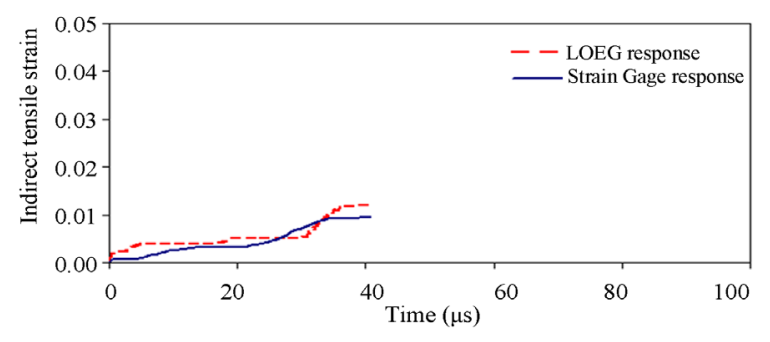

(e)

Figure 6. High-strain rate indirect tensile tests (a) specimen with strain gage; (b) Wheatstone bridge circuit diagram; (c) specimen mounted in SHPB; (d) simultaneous LOEG and strain gage response from SHPB test; and (e) indirect tensile strain history obtained from LOEG and strain gage responses.

circuit through digital strain indicator system (Model P-3500 from Vishay Measurements Group). The dynamic data was transmitted to oscilloscope and stored in memory card. This dynamic response was plotted as the indirect tensile strain-time history of the disk specimen. Simultaneously LOEG setup provided comparative strain response to the same oscilloscope. In this comparative investigation, a similar strain-time history was obtained from both the strain-gage and LOEG responses (Figure 6(e)); thus validated the application of LOEG for indirect tensile strain measurement.

\subsection{Quasi-Static Indirect Tensile Test Set-Up}

Quasi-static indirect tensile experiments were conducted on EnduraTec, a pneumatically driven materials test system (Figure 7(a)) for evaluating the strain-rate effects over a broad range of loading. An interface load cell was used to measure the axial load. The disk specimen was mounted diametrically within the same concave end fixtures for obtaining identical boundary condition applied in SHPB tests. LOEG unit was oriented transversely with respect to the loading axis for measuring the induced transverse tensile strain in disk specimen.

\subsection{Material Description}

Quasi-static indirect tensile experiments were conducted on EnduraTec, a pneumatically driven materials test 


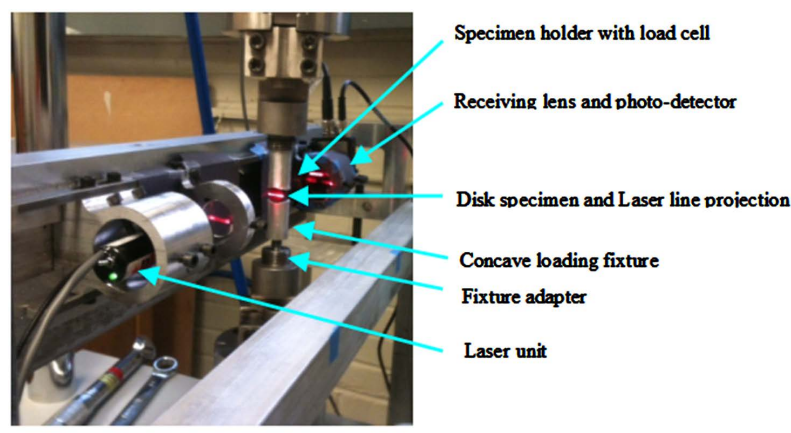

(a)

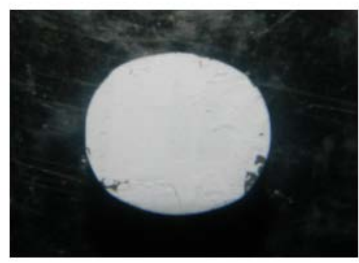

(b)

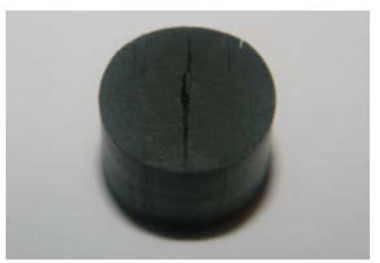

(c)

Figure 7. (a) Quasi-static indirect tensile test setup; (b) post-test pure vinyl ester sample deformed elliptically without splitting; (b) reinforced nanocomposite with diametrical splitting.

system (Figure 7(a)) for evaluating the strain-rate effects over a broad range of loading. An interface load cell was used to measure the axial load. The disk specimen was mounted diametrically within the same concave end fixtures for obtaining identical boundary condition applied in SHPB tests. LOEG unit was oriented transversely with respect to the loading axis for measuring the induced transverse tensile strain in disk specimen. Five different DERAKANE 510A-40 vinyl ester thermoset nanocomposite panels [20] were considered for the dynamic indirect tensile characterization. The brominated bisphenol-A based vinyl ester consists of 38 weight \% styrene, added with Butanone peroxide, N,N-Dimethylaniline, Cobalt Naphthenate and 2-4-Pentanedione additives to impart maximum fire retardance, chemical resistance and toughness. Pure brominated vinyl ester polymer (VE) was reinforced with 1.25 weight $\%$ and 2.5 weight $\%$ exfoliated graphite nanoplatelates $(1.25 \mathrm{xGnP}+\mathrm{VE}$ and $2.5 \mathrm{xGnP}+\mathrm{VE}$ respectively) in two different batches. One of the reinforced nanocomposite batches was toughened with 10 weight \% almost unreactive liquid carboxyl terminated butadiene nitrile (CTBN) rubber $(1.25 \mathrm{xGnP}+\mathrm{CTBN}+\mathrm{VE}$ and $2.5 \mathrm{xGnP}+\mathrm{CTBN}+\mathrm{VE})$. The nanoplatelets were exfoliated and homogeneously dispersed in polymer matrix by applying sonication technique. The solution of vinyl ester resin with nanoreinforcement and toughening agent was poured into a mold, kept at room temperature for 30 minutes and then post cured at $80^{\circ} \mathrm{C}$ for 3 hours [32].

Nanocomposite disk specimens with a diameter of $12.7 \mathrm{~mm}$ ( 0.5 inch) were machined using carbide tipped tool in CNC machine from $101.4 \mathrm{~mm} \times 101.4 \mathrm{~mm}$ (12 inch $\times 12$ inch) molded panels with thickness of $10 \mathrm{~mm}$ (0.4 inch). The diameter of specimen was decided based on the dynamic pulse duration through the diameter of the specimen. The pulse-wave needs to reverberate more than three times before failure initiation to ensure dynamic stress equilibrium in the specimen. The pulse speed in the specimen was predicted based on quasi-static properties (Table 1) that were obtained [34] according to ASTM 638-08 [51] using typical dog-bone specimen geometry.

\section{Experimental Results and Discussion}

Figure 8 shows the typical splitting of a disk specimen due to diametrical compressive loading at high-strain rate in SHPB. The induced indirect tensile stress developed at the center of the specimen splits the specimen along the horizontal loading axis with an enlargement of the transverse diameter. It is to be noted that the tensile strength and the energy absorbing capacity of the specimen is recorded and determined only until the diametrical splitting occurs. Any further disintegration of the specimen has no relevance to this investigation. Figure 9(a) shows a typical SHPB and LOEG response of high strain rate indirect tensile test. The initiation of a crack in the specimen is indicated as per the instantaneous drop (Figure 9(b)) of stress when the specimen is under equilibrium loading condition. As the prominent first stress peak (considered as dynamic indirect tensile strength) was observed in the stress-time history, the corresponding time has been taken as the time-instant of the crack-initiation phenomenon. The corresponding strain developed (Figure 9(c)) at that time-instant is designated as the ultimate tensile strain of the specimen under indirect tensile loading. The energy absorbing capacity $(E)$, i.e., the energy necessary to deform a specimen per unit volume, is evaluated by integrating the area (Figure 9(d)) under the stress vs. strain curve [52] using the following Equation 


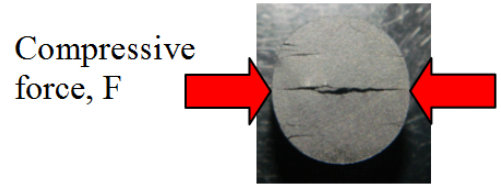

Figure 8. Typical splitting of disk specimen under induced indirect tensile stress.

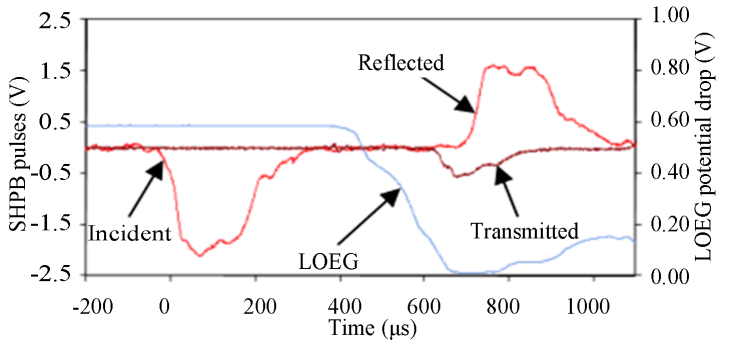

(a)

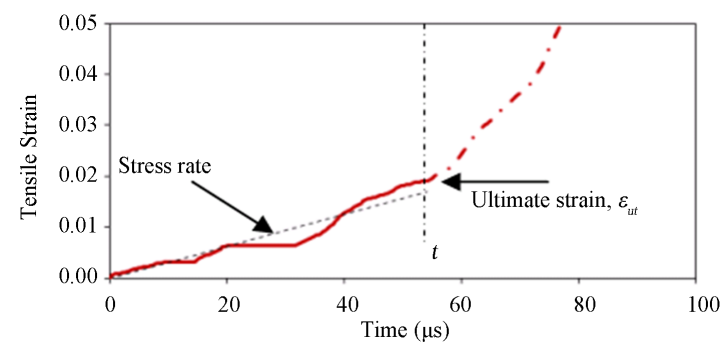

(c)

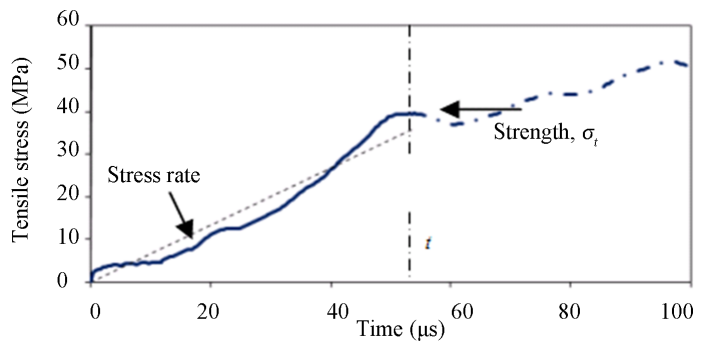

(b)

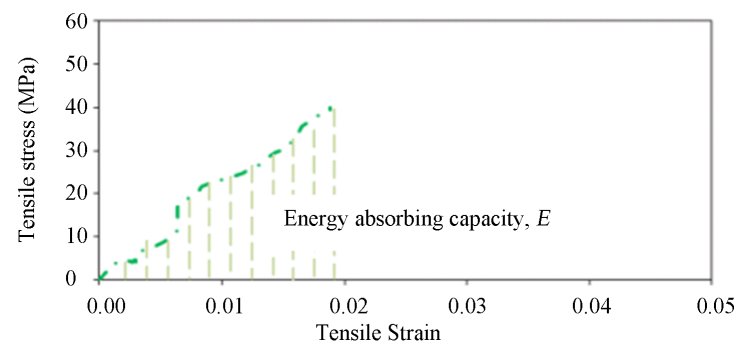

(d)

Figure 9. Typical SHPB and LOEG response of vinyl ester nanocomposites in high strain rate indirect tensile test: (a) SHPB and LOEG response; (b) stress-time history; (c) strain-time history; and (d) energy absorbing capacity estimation from stress-strain curve.

Table 1. Quasi-static direct tensile properties of nanocomposites [34] tested according to ASTM 638-08 using dog-bone specimen geometry [51].

\begin{tabular}{cccccccc}
\hline Matrix & Reinforcement & Toughening Agent & $\begin{array}{c}\text { Density } \\
\left(\mathrm{kg} / \mathrm{m}^{3}\right)\end{array}$ & $\begin{array}{c}\text { Poisson's Ratio } \\
\text { Modulus (GPa) }\end{array}$ & $\begin{array}{c}\text { Strength (MPa) } \\
\text { Ultimate strain } \\
(\%)\end{array}$ \\
\hline Brominated Vinyl ester & None & None & 1338 & 0.37 & 3.49 & 81.5 & 3.14 \\
Brominated Vinyl ester & $1.25 \mathrm{wt} \%$ xGnP & None & 1352 & 0.35 & 3.82 & 39.1 & 1.28 \\
Brominated Vinyl ester & $2.5 \mathrm{wt} \%$ xGnP & None & 1363 & 0.35 & 3.71 & 42.6 & 1.68 \\
Brominated Vinyl ester & $1.25 \mathrm{wt} \%$ xGnP & $10 \mathrm{wt} \%$ CTBN & 1337 & 0.35 & 4.68 & 45.7 & 1.48 \\
Brominated Vinyl ester & $1.25 \mathrm{wt} \%$ xGnP & $10 \mathrm{wt} \%$ CTBN & 1343 & 0.38 & 5.22 & 26.0 & 0.61 \\
\hline
\end{tabular}

$$
E=\int_{0}^{\varepsilon_{u t}} \sigma_{t}(\varepsilon) \mathrm{d} \varepsilon
$$

where, $\sigma_{t}$ is the induced tensile stress, $\varepsilon$ is the corresponding transverse diametrical tensile strain and $\varepsilon_{u t}$ is the ultimate strain.

\subsection{Quasi-Static Indirect Tensile Response}

The quasi-static $\left(0.015 \mathrm{~mm} / \mathrm{s}\right.$ displacement controlled at $0.001 \mathrm{~s}^{-1}$ strain rate) indirect tensile response shows a detrimental effect of the inclusion of $\mathrm{xGnP}$ and CTBN to pristine vinyl ester (Table 2). The pure vinyl ester specimens (Figure 7(b)) showed ductile deformation response beyond the load cell limit (10 kN). Hence, the 
conventional Brazilian disk test method, which is appropriate for brittle materials, could not capture the true behavior of pure vinyl ester under quasi-static loading due to its ductility. It is, therefore, recognized that the modulus, strength and failure strain data for pure vinyl ester as reported in Table 2 are not meaningful. However, addition of $\mathrm{xGnP}$ and CTBN makes the vinyl ester polymer more brittle (Figure 7(c)) and thus suitable for this indirect experimental method. The quasi-static indirect tensile response (Table 2) agrees reasonably with previous investigations performed [34] according to ASTM 638-08 [51], using dog-bone specimen geometry (Table 1).

The quasi-static indirect tensile stress-strain history for pure vinyl ester, $\mathrm{xGnP}$ reinforced and CTBN toughened samples is shown in Figure 10. As mentioned earlier, stress-strain plots for only the pure vinyl ester

Table 2. Quasi-static indirect tensile properties of nanocomposites obtained from Brazilian disk test method.

\begin{tabular}{cccccc}
\hline Matrix & Reinforcement & Toughening Agent & Elastic Modulus (GPa) & Strength (MPa) & Ultimate Strain (\%) \\
\hline Brominated Vinyl Ester & None & None & 1.29 & 35.9 & 3.38 \\
Brominated Vinyl Ester & $1.25 \mathrm{wt} \%$ xGnP & None & 3.93 & 26.8 & 1.50 \\
Brominated Vinyl Ester & $2.5 \mathrm{wt} \% \mathrm{xGnP}$ & None & 3.73 & 29.8 & 0.98 \\
Brominated Vinyl Ester & $1.25 \mathrm{wt} \% \mathrm{xGnP}$ & $10 \mathrm{wt} \% \mathrm{CTBN}$ & 4.49 & 29.1 & 2.13 \\
Brominated Vinyl Ester & $1.25 \mathrm{wt} \% \mathrm{xGnP}$ & $10 \mathrm{wt} \% \mathrm{CTBN}$ & 5.14 & 27.6 & 1.34 \\
\hline
\end{tabular}

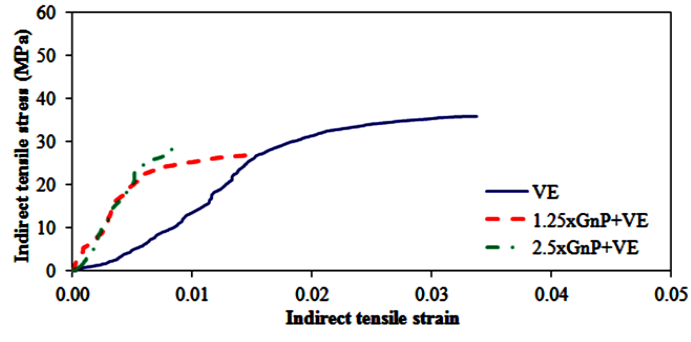

(i-a)

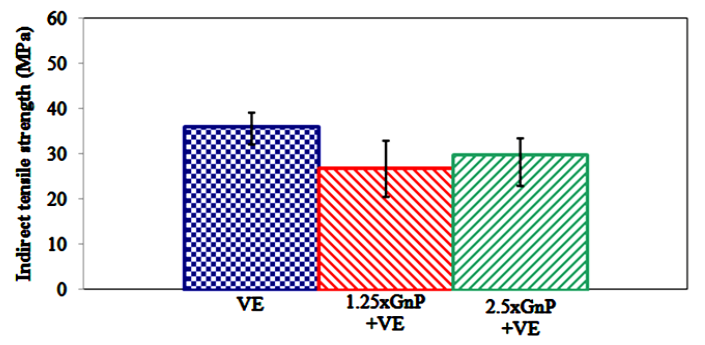

(ii-a)

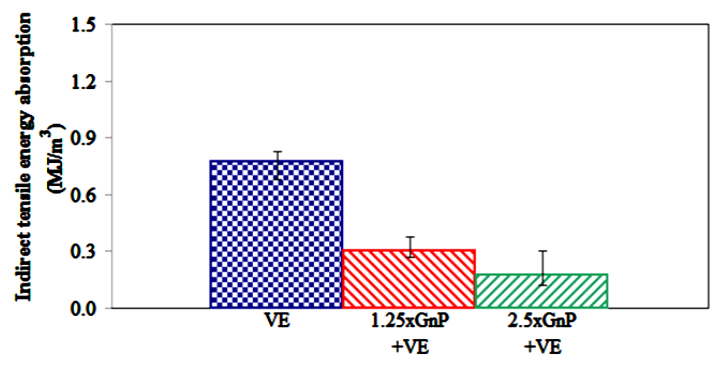

(iii-a)

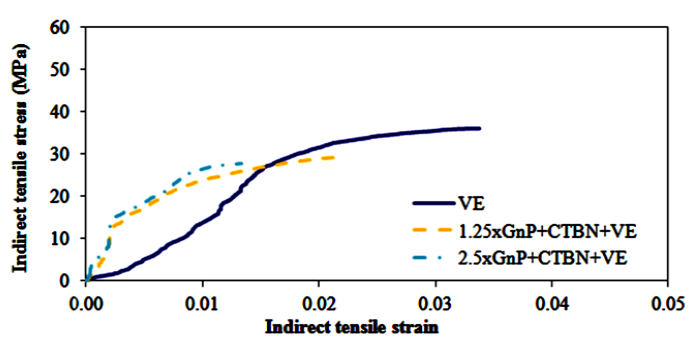

(i-b)

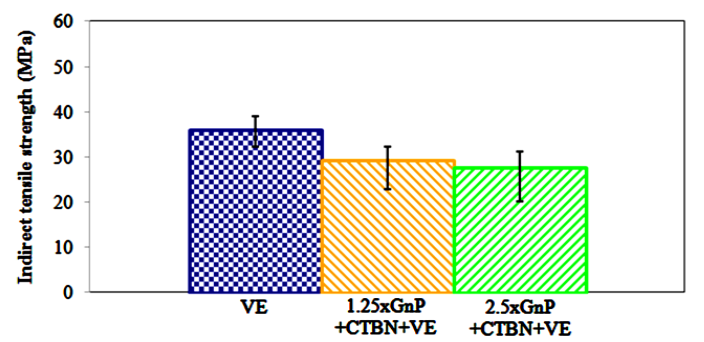

(ii-b)

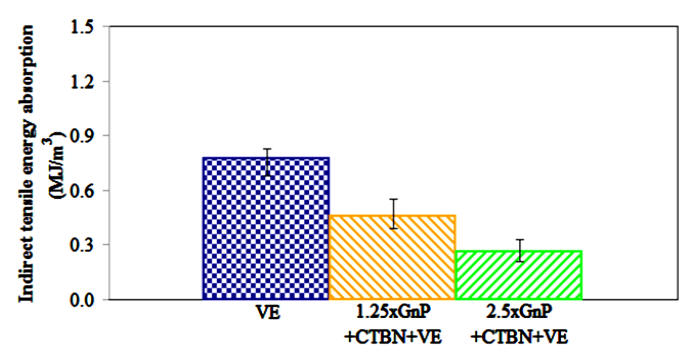

(iii-b)

Figure 10. Quasi-static indirect tensile response (i) typical stress vs. strain behavior, (ii) strength, and (iii) energy absorbing capacity of; (a) graphite platelet reinforced; and (b) with additional CTBN toughened vinyl ester nanocomposites [note: pure vinyl ester specimens did not fail within the $10 \mathrm{kN}$ load cell limit of test equipment used for quasi-static testing]. 


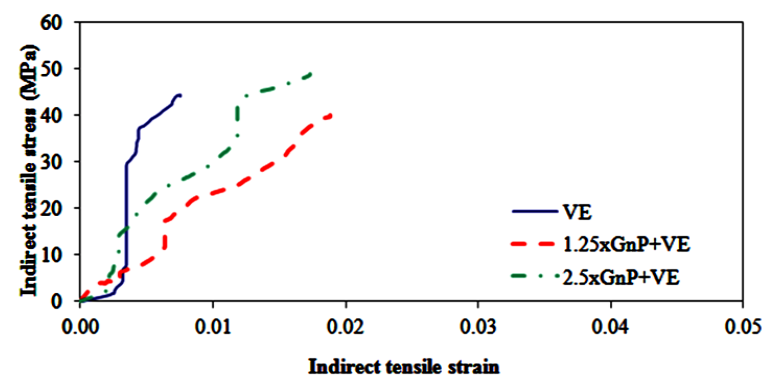

(i-a)

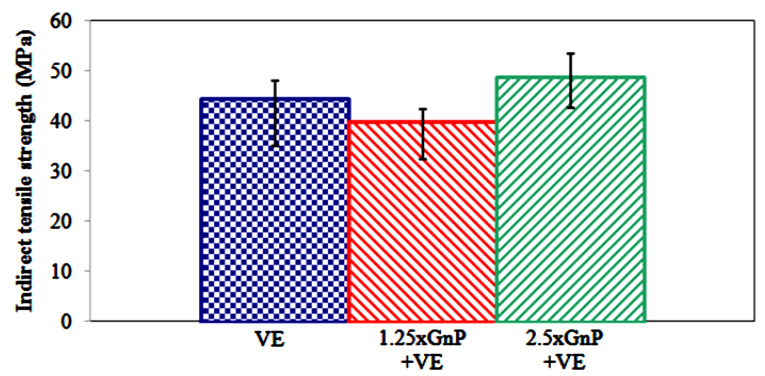

(ii-a)

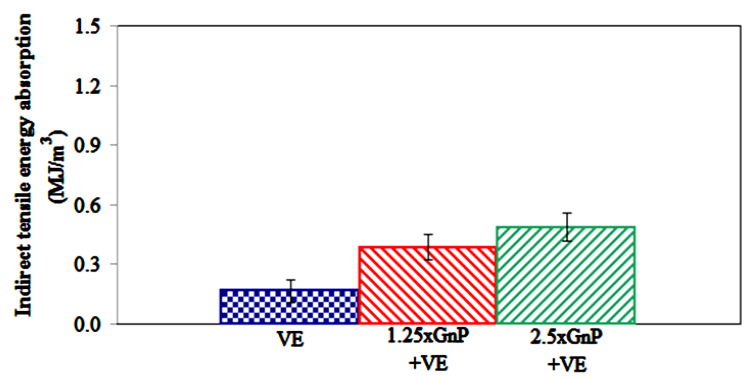

(iii-a)

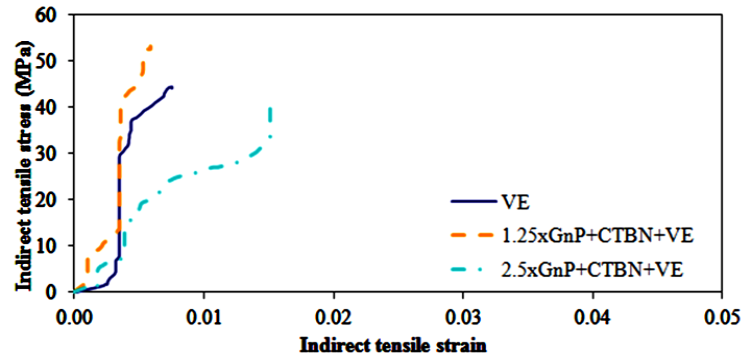

(i-b)

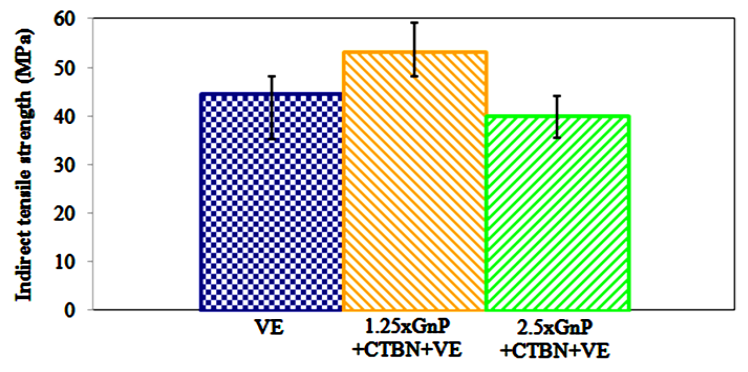

(ii-b)

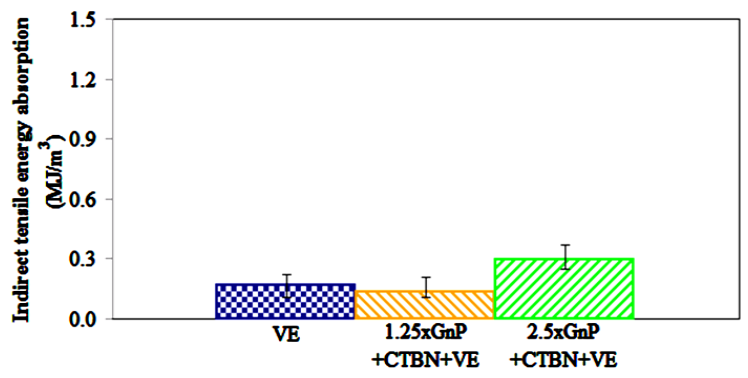

(iii-b)

Figure 11. High-strain rate indirect tensile response from SHPB tests (i) typical stress vs. strain behavior, (ii) strength, and (iii) energy absorbing capacity of; (a) graphite platelet reinforced; and (b) additionally CTBN toughened vinyl ester nanocomposites.

specimens have been terminated due to load cell capacity before the specimen failure occurs, whereas all reinforced samples failed within the load cell range.

It can be observed in Figure 10(ii) that tensile strength of pure vinyl ester is reduced by the addition of $\mathrm{xGnP}$ reinforcement (Figure 10(ii-a)), and even with CTBN toughening (Figure 10(ii-b)).

Energy absorbing capacity (Figure 10(iii)) is similarly affected by the addition of xGnP (Figure 10(iii-a)). The addition of CTBN did not improve the energy absorbing capacity (Figure 10(iii-b)) of pure vinyl ester, however, a marginal enhancement (Figure 10(iii-b)) can be observed when compared to only xGnP reinforced (i.e., without CTBN, Figure 10(iii-a)) nanocomposites.

\subsection{Dynamic Indirect Tensile Response}

Figure 11 summarizes the indirect tensile high-strain rate response of $\mathrm{xGnP}$ reinforced and with additional CTBN toughened vinyl ester nanocomposites at strain-rate of $1000 \mathrm{~s}-1$ from SHPB tests. All of the nanoreinforced specimens including pure vinyl ester failed in a brittle manner under dynamic tensile loading (Figure 11(i)).

It can be observed that the tensile strength of pure vinyl ester remains unchanged with $x \mathrm{GnP}$ reinforcement (Figure 11(ii-a)). Addition of CTBN toughening to the $1.25 \mathrm{wt} \% \mathrm{xGnP}$ reinforced nanocomposites showed a marginal improvement (Figure 11(ii-b)). The energy absorbing capacity of pure vinyl ester is improved with 
$\mathrm{xGnP}$ (Figure 11(iii-a)) reinforcement. However, this improvement is reduced about $50 \%$ by further CTBN toughening to the $\mathrm{xGnP}$ reinforced nanocomposites (Figure 11(iii-b)).

\subsection{Strain Rate Effect}

Comparative observation of Figure 10 and Figure 11 shows the strain-rate dependency of tensile strength and energy absorbing capacity of these candidate materials. As noted earlier, during quasi-static tests pure vinyl ester did not fail within maximum load limit of the load cell used, deforming elliptically in a ductile manner (Figure 7(b) and Figure 10(i)). However, it failed in a brittle fashion at much lesser strain (Figure 11(i)) under the high-strain rate SHPB loading. This ductile-to-brittle transition may be due to the significant influence of strain-rate effect. These nanocomposites can be considered as thermo-viscoelastic under high-strain rate loading in Hopkinson bar experiments, and the time-temperature superposition principle would be applicable for characterizing their response. A higher strain rate would correspond to a shorter loading time, equivalent to lower temperatures [14] causing the ductile-to-brittle transition of the specimen. This phenomenon has been further explained by the authors applying a technique of measuring fractal parameters of the fractured surfaces on the same candidate materials [38].

About 25\% increment in tensile strength is observed at high-strain rate loading (Figure 11(ii)) with respect to the quasi-static response (Figure 10(ii)). The energy absorption capacity of pure vinyl ester is adversely affected under high-strain rate loading, whereas it is improved with the addition of xGnP reinforcement (Figure 10(iii-a) and Figure 11(iii-a)). However, additional CTBN toughening agent could not contribute towards increasing the energy absorbing capacity (Figure 10(iii-b) and Figure 11(iii-b)).

\section{Conclusions}

An indirect tensile testing method is proposed for the high-strain rate dynamic characterization of high stiffness and low strength graphite platelet reinforced vinyl ester nanocomposites. Salient features of the proposed technique include:

- Traditional Brazilian disk test method is combined with conventional split-Hopkinson pressure bar (SHPB) technique.

- Considering Brazilian disk specimen simplifies the complex geometry of conventional direct tensile test specimen and the loading fixture. The two concave-end loading fixtures assembled in between incident and transmission bars of SHPB system ensures easy, secured and self-aligned gripping of the disk specimen.

- Adapting a non-contact Laser Occluding Expansion Gage eliminates the complexities of conventional strain gage application for measuring the transverse diametrical expansion of the disk specimen under high-strain rate diametrical compressive loading.

- High-speed digital photography diagnosis validates the specimen failure mechanism in this indirect test method for characterizing the tensile properties of graphite platelet reinforced and additionally CTBN toughened vinyl ester nanocomposites.

- The conventional Brazilian disk test method could not capture true behavior of the apparently ductile pure vinyl ester under quasi-static loading.

Quasi-static and dynamic experimental investigations characterized the contribution of xGnP reinforcement along with CTBN toughening on the tensile properties of vinyl ester based nanocomposites and the effect of strain rate. The key observations in this investigation are:

- Tensile strength and energy absorbing capacity of pure vinyl ester is reduced by the addition of xGnP reinforcement and even with CTBN toughening under quasi-static loading.

- Addition of CTBN marginally improved the energy absorbing capacity of the only xGnP reinforced (without CTBN) nanocomposites under quasi-static loading.

- Tensile strength of pure vinyl ester remains almost the same with addition of $x G n P$ reinforcement and even with CTBN toughening under high-strain rate loading.

- Energy absorbing capacity of pure vinyl ester is improved with addition of $x G n P$ reinforcement under high-strain rate loading.

- Pure vinyl ester shows ductile-to-brittle transition from quasi-static to high-strain rate loading.

- Tensile strength observed in quasi-static test is increased at high strain-rate loading for these candidate nanocomposites. 
- The energy absorption capacity of pure vinyl ester is adversely affected under high-strain rate loading.

\section{Acknowledgements}

Office of Naval Research, Solid Mechanics Program (Dr. Yapa D. S. Rajapakse, Program Manager), Grant No. N00014-7-1-1010; and US Army Research Office under the DOD-PIRT sub-contracted through North Carolina A \& T University Grant No. 300223243A provided partial supports for this research. Dr. Larry Drzal's group at Michigan State University manufactured the vinyl ester nanocomposite panels. Mr. Andy Gossett, Machineshop Supervisor at the University of Mississippi machined disk specimens and fabricated all components required for developing the experimental technique.

\section{References}

[1] Gray III, G.T. (2000) Classic Split Hopkinson Bar Testing. ASM Handbook, Mechanical Testing and Evaluation, 8, 462-476.

[2] Hopkinson, B. (1914) A Method of Measuring the Pressure Produced in the Detonation of High Explosives or by the Impact of Bullets. Philosophical Transactions of the Royal Society London Series A, 213, 437-456. http://dx.doi.org/10.1098/rsta.1914.0010

[3] Davies, R.M. (1948) A Critical Study of the Hopkinson Pressure Bar. Philosophical Transactions of the Royal Society of London Series A, Mathematical and Physical Sciences, 240, 375-457. http://dx.doi.org/10.1098/rsta.1948.0001

[4] Kolsky, H. (1949) An Investigation of the Mechanical Properties of Materials at Very High Rates of Strain. Proceedings of the Physical Society, Section B, 62, 676-700. http://dx.doi.org/10.1088/0370-1301/62/11/302

[5] Harding, J., Wood, E.O. and Campbell, J.D. (1960) Tensile Testing of Materials at Impact Rates of Strain. Journal of Mechanical Engineering Science, 2, 88-96. http://dx.doi.org/10.1243/JMES_JOUR_1960_002_016_02

[6] Lindholm, U.S. and Yeakley, L.M. (1968) High Strain-Rate Testing: Tension and Compression. Experimental Mechanics, 8, 1-9. http://dx.doi.org/10.1007/BF02326244

[7] Albertini, C. and Montagnani, M. (1974) Mechanical Properties at High Rates of Strain. Institute of Physics, London, 22.

[8] Kawata, K., Hashimoto, S., Kurokawa, K. and Kanayama, N. (1979) A New Testing Method for the Characterization of Materials in High-Velocity Tension. The Institute of Physics, 47, 71-80.

[9] Nicholas, T. (1980) Tensile Testing of Materials at High Rates of Strain. Experimental Mechanics, 21, 177-185. http://dx.doi.org/10.1007/BF02326644

[10] Rajendran, A.M. and Bless, S.J. (1986) Determination of Tensile Flow Stress beyond Necking at Very High Strain Rate. Experimental Mechanics, 26, 319-323. http://dx.doi.org/10.1007/BF02320146

[11] Staab, G.H. and Gilat, A. (1991) A Direct-Tension Split Hopkinson Bar for High-Strain Rate Testing. Experimental Mechanics, 31, 232-235. http://dx.doi.org/10.1007/BF02322543

[12] Li, M., Wang, R. and Han, M.B. (1993) A Kolskey Bar: Tension, Tension-Tension. Experimental Mechanics, 33, 7-14. http://dx.doi.org/10.1007/BF02322543

[13] Melin, L.G., Stahle, P. and Sundin, K.G. (1998) High Strain Rate Tensile Using Microscopic High Speed Photography. 11th International Conference on Experimental Mechanics, Oxford, 24-28 August 1998, 175-179.

[14] Chen, W., Lu, F. and Cheng, M. (2002) Tension and Compression Tests of Two Polymers under Quasi-Static and Dynamic Loading. Polymer Testing, 21, 113-121. http://dx.doi.org/10.1016/S0142-9418(01)00055-1

[15] Sharma, A., Shukla, A. and Prosser, R.A. (2002) Mechanical Characterization of Soft Materials Using High Speed Photography and Split Hopkinson Pressure Bar Technique. Journal of Materials Science, 37, 1005-1017. http://dx.doi.org/10.1023/A:1014308216966

[16] Gilat, A., Goldberg, R.K. and Roberts, G.D. (2005) Strain Rate Sensitivity of Epoxy Resin in Tensile and Shear Loading. NASA/TM-2005-213595, 1-33.

[17] Owens, A.T. and Tippur, H.V. (2009) A Tensile Split Hopkinson Bar for Testing Particulate Polymer Composites under Elevated Rates of Loading. Experimental Mechanics, 47, 799-811. http://dx.doi.org/10.1007/s11340-008-9192-7

[18] Chen, R., Dai, F., Lu, L., Lu, F. and Xia, K. (2010) Determination of Dynamic Tensile Properties for Low Strength Brittle Solids. Experimental and Applied Mechanics, 6, 321-326.

[19] (2011) Resin Systems for Use in Fiber-Reinforced Composite Materials. Vinyl Ester Resin, Article ID: 986, Source: SP Systems. http://www.azom.com/

[20] Ashland Inc. (2011) DERAKANE 510A-40 Epoxy Vinyl Ester Resin. Technical Datasheet, Document 1775V2 F2, 
Language EN V1, Approved 2008-9-8: 1-4.

[21] Shivakumar, K.N., Swaminathan, G. and Sharpe, M. (2006) Carbon Vinyl Ester Composites for Enahanced Performance in Marine Applications. Journal of Reinforced Plastics and Composites, 25, 1101-1116. http://dx.doi.org/10.1177/0731684406065194

[22] Chung, D.D.L. (1987) Exfoliation of Graphite. Journal of Material Science, 22, 4190-4198. http://dx.doi.org/10.1007/BF01132008

[23] Yoshida, A., Hishiyama, Y. and Inagaki, M. (1991) Exfoliated Graphite from Various Intercalation Compounds. Carbon, 29, 1227-1231. http://dx.doi.org/10.1016/0008-6223(91)90040-P

[24] Giannelis, E.P. (1996) Polymer Layered Silicate Nanocomposites. Advanced Materials, 8, 29-35. http://dx.doi.org/10.1002/adma.19960080104

[25] Auad, M.L.P., Frontini, M., Borrajo, J. and Aranguren, M.I. (2001) Liquid Rubber Modified Vinyl Ester Resins: Fracture and Mechanical Behavior. Polymer, 42, 3723-3730. http://dx.doi.org/10.1016/S0032-3861(00)00773-4

[26] Celzard, A., Schneider, S. and Marêché, J.F. (2002) Densificaton of Expanded Graphite. Carbon, 40, 2185-2191. http://dx.doi.org/10.1016/S0008-6223(02)00077-5

[27] Toshiaki, E., Masatsugu, S. and Morinobu, E. (2003) Graphite Intercalation Compounds and Applications. Oxford University Press, Inc., New York.

[28] Fröhlich, J., Thomann, R. and Mülhaupt, R. (2003) Toughened Epoxy Hybrid Nanocomposites Containing both an Organophilic Layered Silicate Filler and a Compatibilized Liquid Rubber. Macromolecules, 36, 7205-7211. http://dx.doi.org/10.1021/ma035004d

[29] Yasmin, A. and Daniel, I. (2004) Mechanical and Thermal Properties of Graphite Platelet/Epoxy Composites. Polymer, 45, 8211-8219. http://dx.doi.org/10.1016/j.polymer.2004.09.054

[30] Fukushima, H. and Drzal, L.T. (2004) Graphite Nanoplatelets as Reinforcement for Polymers: Structural and Electrical Properties. Proceedings of 17th International Conference on American Society for Composites.

[31] Balakrishnan, S., Start, P.R., Raghavan, D. and Hudson, S.D. (2005) The Influence of Clay and Elastomer Concentration on the Morphology and Fracture Energy of Preformed Acrylic Rubber Dispersed Clay Filled Epoxy Nanocomposites. Polymer, 46, 11255-11262. http://dx.doi.org/10.1016/j.polymer.2005.10.053

[32] Drzal, L.T. and Fukushima, H. (2006) Exfoliated Graphite Nanoplatelets (Xgnp): A Carbon Nanotube Alternative. The Nanotechnology Conference, Boston, 7-11 May 2006.

[33] Lu, J., Do, I., Drzal, L.T., Worden, R.M. and Lee, I. (2008) Nanometal-Decorated Exfoliated Graphite Nanoplatelet Based Glucose Biosensors with High Sensitivity and Fast Response. ACS Nano, 2, 1825-1832. http://dx.doi.org/10.1021/nn800244k

[34] Magableh, A. (2010) Viscoelastic and Shock Response of Nanoclay and Graphite Platelet Reinforced Vinyl Ester Nanocomposites. Ph.D. Dissertation, Department of Mechanical Engineering, University of Mississippi, Oxford.

[35] Mantena, P.R., Cheng, A.H.D., Al-Ostaz, A. and Rajendran, A.M. (2010) Blast and Impact Resistant Composite Structures for Navy Ships. Proceedings of Marine Composites and Sandwich Structures, Office of Naval Research-Solid Mechanics Program Review, Adelphi, 27-29 September 2010.

[36] Pramanik, B. and Mantena, P.R. (2011) Viscoelastic Response of Graphite Platelet and CTBN Reinforced Vinyl Ester Nanocomposites. Materials Sciences and Applications, 2, 1667-1674. http://dx.doi.org/10.4236/msa.2011.211222

[37] Pramanik, B. and Mantena, P.R. (2012) Energy Absorption of Nano-Reinforced and Sandwich Composites in Ballistic and Low-Velocity Punch-Shear. Open Journal of Composite Materials, 2, 87-96. http://dx.doi.org/10.4236/ojcm.2012.23010

[38] Pramanik, B., Tadepalli, T. and Mantena, P.R. (2012) Surface Fractal Analysis for Estimating the Fracture Energy Absorption of Nanoparticle Reinforced Composites. Materials, 5, 922-936. http://dx.doi.org/10.3390/ma5050922

[39] Carneiro, F.L.L.B. and Barcellos, A. (1953) Resistance a La Traction Des Betons. Bulletin RILEM, 13, 97-108.

[40] Akazawa, T. (1953) Tension Test Method for Concretes. Bulletin RILEM, 16, 13-23.

[41] Thimoshenko, S. and Goodier, J.N. (1951) Theory of Elasticity. McGraw-Hill Book Co., Inc., New York, 107-111.

[42] Pramanik, B. (2013) High-Strain Rate Tensile Characterization of Graphite Platelet Reinforced Vinyl Ester Nanocomposites Using Split-Hopkinson Pressure Bars. Ph.D. Dissertation, Department of Mechanical Engineering, University of Mississippi, Oxford.

[43] Pramanik, B. and Mantena, P.R. (2014) Strain Rate Dependent Ductile-to-Brittle Transition of Graphite Platelet Reinforced Vinyl Ester Nanocomposites. Advances in Materials Science and Engineering, 2014, Article ID: 765698. http://dx.doi.org/10.1155/2014/765698

[44] Precision Ground Bars (2013) Grinding Services-Boston Centerless. http://www.bostoncenterless.com/ 
[45] Awaji, H. and Sato, S. (1979) Diametral Compressive Testing Method. Journal of Engineering Materials and Technology, 101, 139-147. http://dx.doi.org/10.1115/1.3443665

[46] Wang, Q.Z., Jia, X.M., Kou, S.Q., Zhang, Z.X. and Lindqvist, P.A. (2004) The Flattened Brazilian Disc Specimen Used for Testing Elastic Modulus, Tensile Strength and Fracture Toughness of Brittle Rocks: Analytical and Numerical Results. International Journal of Rock Mechanics \& Mining Sciences, 41, 245-253. http://dx.doi.org/10.1016/S1365-1609(03)00093-5

[47] Wertheimer (1912) Experimentelle Studien Über Das Sehen Von Bewegung. Zeitschriftfür Psychologie, 61, $161-265$.

[48] Chen, R., Xia, K., Dai, F., Lu, F. and Luo, S.N. (2009) Determination of Dynamic Fracture Parameters Using a SemiCircular Bend Technique in Split Hopkinson Pressure Bar Testing. Engineering Fracture Mechanics, 101, 1268-1276. http://dx.doi.org/10.1016/j.engfracmech.2009.02.001

[49] Frew, D.J., Forrestal, M.J. and Chen, W. (2002) Pulse Shaping Techniques for Testing Brittle Materials with a Split Hopkinson Pressure Bar. Experimental Mechanics, 42, 93-106. http://dx.doi.org/10.1007/BF02411056

[50] Chen, R., Dai, F., Qin, J. and Lu, F. (2013) Flattened Brazilian Disc Method for Determining the Dynamic Tensile Stress-Strain Curve of Low Strength Brittle Solids. Experimental Mechanics, 53, 1153-1159. http://dx.doi.org/10.1007/s11340-013-9733-6

[51] (2008) ASTM Standard D 638-08. Standard Test Method for Tensile Properties of Plastics. ASTM International.

[52] Yi, F., Zhu, Z., Zu, F., Hu, S. and Yi, P. (2001) Strain Rate Effects on the Compressive Property and the Energy-Absorbing Capacity of Aluminum Alloy Foams. Materials Characterization; 47, 417-422. http://dx.doi.org/10.1016/S1044-5803(02)00194-8 
Scientific Research Publishing (SCIRP) is one of the largest Open Access journal publishers. It is currently publishing more than 200 open access, online, peer-reviewed journals covering a wide range of academic disciplines. SCIRP serves the worldwide academic communities and contributes to the progress and application of science with its publication.

Other selected journals from SCIRP are listed as below. Submit your manuscript to us via either submit@scirp.org or Online Submission Portal.
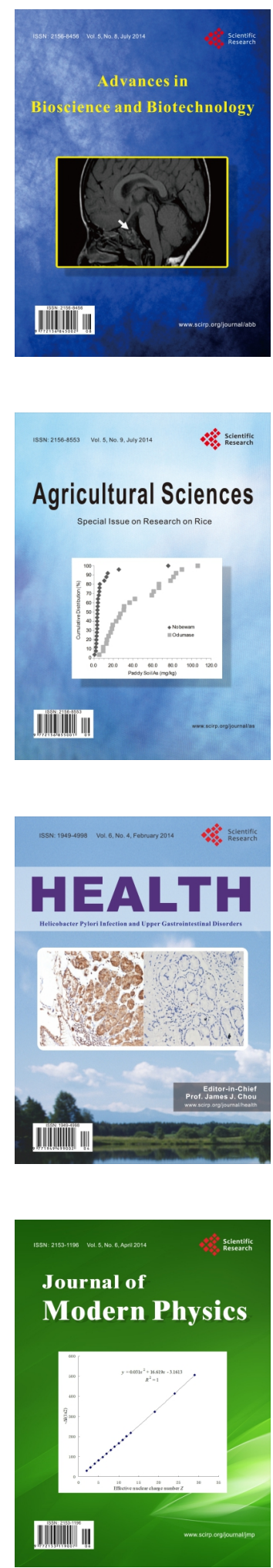
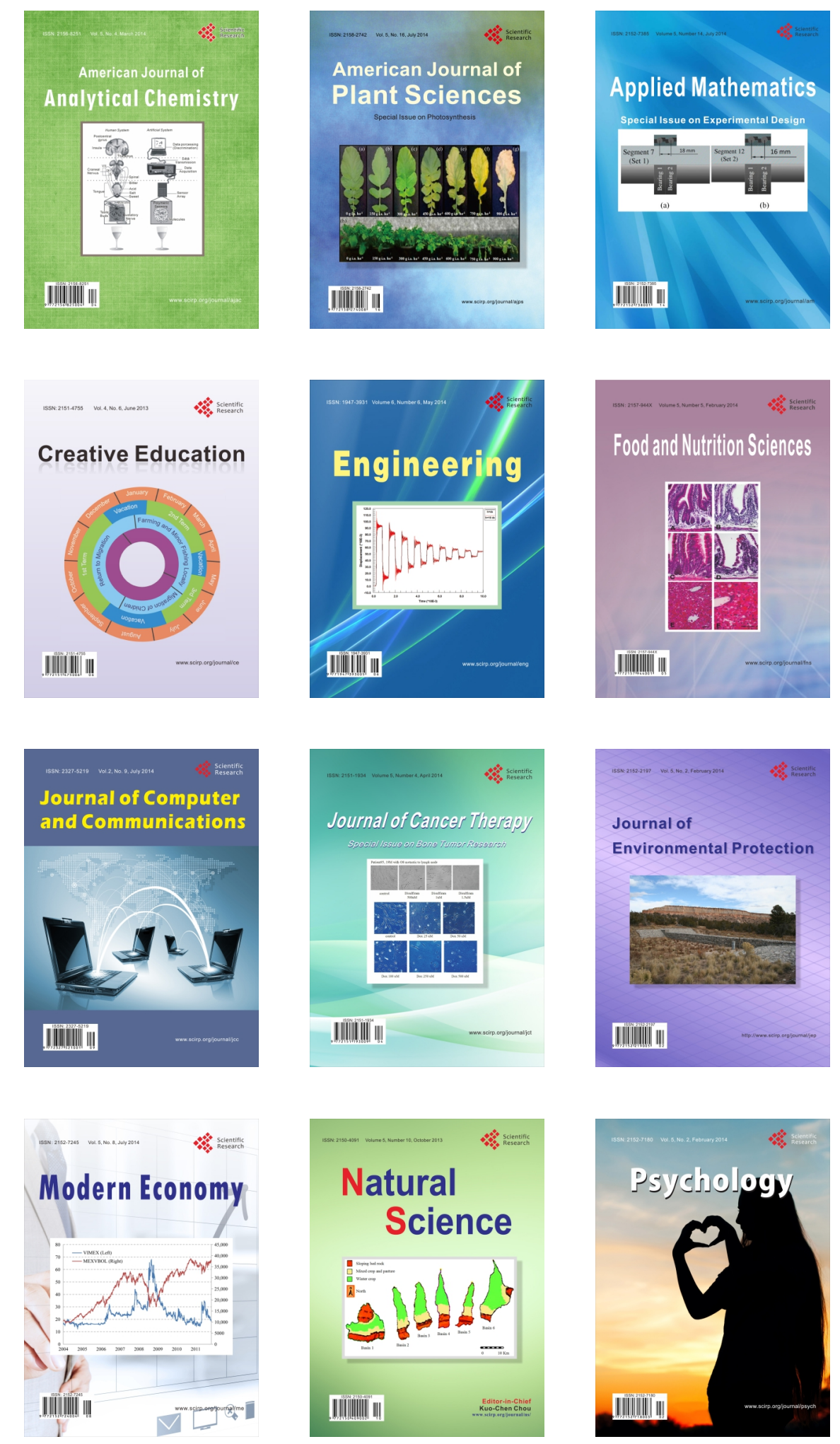